\title{
Research on Lemongrass Oil Extraction Technology (Hydrodistillation, Microwave-Assisted Hydrodistillation)
}

\author{
Thien Hien Tran ${ }^{1}$, Duy Chinh Nguyen ${ }^{1}$, Thuong Nhan Nguyen Phu ${ }^{1}$, Van Thi Thanh Ho ${ }^{2}$, \\ Dai Viet Nguyen Vo $^{3}$, Long Giang Bach ${ }^{1}$, and Trinh Duy Nguyen ${ }^{1, *}$
}

${ }^{1}$ NTT Hi-Technology Institute, Nguyen Tat Thanh University, Ho Chi Minh City 755000, Vietnam

${ }^{2}$ Ho Chi Minh University of Natural Resources and Environment (HCMUNRE), Vietnam

${ }^{3}$ Faculty of Chemical and Natural Resources Engineering, Universiti Malaysia Pahang,

Lebuhraya Tun Razak 26300, Gambang, Pahang, Malaysia

\section{* Corresponding author: \\ email:ndtrinh@ntt.edu.vn \\ Received: August 3, 2018 \\ Accepted: December 1, 2018}

DOI: $10.22146 /$ ijc. 40883

\begin{abstract}
Microwave-assisted hydrodistillation (MAHD) is preferred to traditional extraction methods due to shorter extraction time, the inability of volatile components to be damaged or decomposed which in turn improve the efficiency and quality of essential oils. In this research, we investigated the parameters that affect the extraction of lemongrass oil process by MAHD method and compare with those of hydrodistillation (HD) method. Four parameters were identified which are: raw material size, raw material to water ratio, extraction time and microwave power. The results show that the optimum condition for determining the lemongrass essential oil content is $20 \mathrm{~mm}$ in the 90 min extraction time with a microwave power of $450 \mathrm{~W}$ at raw material to water ratio of $1: 3(\mathrm{~g} / \mathrm{mL})$. When compared to the HD method, we found that the yield lemongrass oil of MAHD method is $0.35 \%$ on 90 min and the yield of HD method is $0.2 \%$ on $360 \mathrm{~min}$. The quality of oil samples at different extraction method was evaluated by determining their chemical constituents through GC-MS. The highest identified component is Citral with $93.28 \%$ for MAHD, while the HD was $83.85 \%$. Therefore, MAHD method is highly efficient and shorten the time needed for the extraction of essential oils.
\end{abstract}

Keywords: microwave; microwave-assisted hydrodistillation; hydrodistillation; lemongrass oil; extraction

\section{- INTRODUCTION}

In recent years, many green technologies of extracting essential oils from herbs and plants that have been demonstrated to be advanced through many studies [1-4]. Owing to efficiency in heating, fast heating transfer and environmental-friendliness of the technique, microwave-assisted procedures for volatile extraction of oils have gained in popularity in laboratories and industrial production. The microwave energy has been applied in many areas such as in biodiesel production, chemical synthesis and food processing [1]. Microwave-assisted hydrodistillation (MAHD) is a combination of microwave energy from the microwave oven and traditional hydrodistillation. Some essential oils have been extracted by MAHD such as Piper betle L [2], sandalwood [3], ginger [4], Cinnamomum camphora [5], rosemary [6], Amomum compactum [7], patchouli [8], Satureja hortensis and Satureja montana [9]. The use of microwave-assisted method in essential oil extraction improves both the yield and quality of the essential oil, the shorter extraction period and the faster extraction rate. In addition, the hydrodistillation (HD) is traditional methods for extraction essential oils. However, given the disadvantages that two approaches to MAHD [10-16], this study will examine the factors that influence the extraction of lemongrass oil from MAHD and compare with those of the HD.

The essential oil (E.O.) is a mixture of organic 
compounds that are blended and have a characteristic odor. At room temperatures, most essential oils in liquid form have a density of less than 1 (except for some essential oils more substantial than water such as cinnamon, lilac, etc.), and are insoluble or partially soluble in water and sweet, hot and strong antiseptic. The chemical composition of the essential oils consists of terpenes and oxygen derivatives of terpenes (such as alcohols, aldehydes or ketones). Although there are many such constituents, usually, it is a few significant constituents that contribute to the value and smell characteristics of the essential oil.

Lemongrass is a tropical plant that produces aromatic oils [17]. One genus of lemongrass is Cymbopogon which consists of about 55 species and are native to the tropical and warm climate of Asia, Africa and America [18]. Lemongrass oil is an essential oil extracted from parts of lemongrass such as lemongrass leaf, bulb of lemongrass. Lemongrass oil, as well as lemongrass, has been used in many fields such as food, pharmaceuticals, and industry [19-20]. Because of its Citral composition, the oil has a light yellow color and the smell of lemon flavor. The utility of lemongrass oil is expressed through its main components. To be specific, lemongrass oil is commonly used in traditional medicine and is applied in the production of perfumes and cosmetics [19]. Herein, the study was to determine the optimum conditions for lemongrass oil extraction by MAHD method then compares the yield and composition of the extract obtained with the HD method.

\section{- EXPERIMENTAL SECTION}

\section{Materials}

\section{Plant samples}

Collected from the Mekong Delta provinces of Vietnam, the leaves of lemongrass are washed. According to Madivoli et al. [21], partially dried lemongrass leaves give yield higher essential oils than fresh lemongrass leaves, hence, once collected, the leaves will be dried at $70{ }^{\circ} \mathrm{C}$ for $5 \mathrm{~h}$ and kept in a moisture-free environment. Regarding the size of the material, previous studies indicated that the smaller the size of the material, the higher the yield of the product [22], thus the size of lemongrass leaves in this study was investigated.

\section{Reagents}

Anhydrous sodium sulfate $\left(\mathrm{Na}_{2} \mathrm{SO}_{4}\right)$, purchased from Sigma Aldrich (US), was used to remove water from essential oils and purchased from Sigma Aldrich (US). Deionized water by Milli-Q purification system (Millipore) (Massachusetts, USA) was used as a solvent in the extraction process.

\section{Procedure}

\section{Microwave-assisted hydrodistillation}

The lemongrass oil extraction process was carried out in a domestic microwave oven (Samsung MW71E) connected to the clevenger apparatus for MAHD operation. Experimental set up for the extraction stage is depicted in Fig. 1(a). The Samsung MW71E has an operating power of $100-800 \mathrm{~W}$ with a $250 \mathrm{v}-50 \mathrm{~Hz}$ power source. The microwave-assisted hydrodistillation were conducted at water to raw material ratio of 1:1, 1:2, 1:3, $1: 4$, and $1: 5(\mathrm{~g} / \mathrm{mL})$ at $30,60,90,120$ and $150 \mathrm{~min}$ and operating microwave power of $150,300,450,600$ and $750 \mathrm{~W}$. The flask containing $100 \mathrm{~g}$ of lemongrass (Cymbopogon citratus) and deionized water was placed in the microwave oven cavity. For collection of extracted essential oils, a clevenger apparatus was set on the top, outside the oven.

\section{Hydrodistillation}

In the MAHD process, $100 \mathrm{~g}$ of partially dried lemongrass leaves were placed into a $1000 \mathrm{~mL}$ volume flask connected directly to the clevenger apparatus and heated with Heating Mantle User Manual heater (1000.EU.05, 300 W, Glassco Laboratory Equipment Pvt. Ltd. India). Experimental set up for the extraction stage is illustrated in Fig. 1(b). The HD method added $400 \mathrm{~mL}$ of deionized water along with sample material. Both methods were carried out at the same duration of $360 \mathrm{~min}$.

\section{Analysis of sample}

Different extracts were compared using their yields of essential oil, and the results were presented as a mean value of each experiment. The yield of essential oil was 


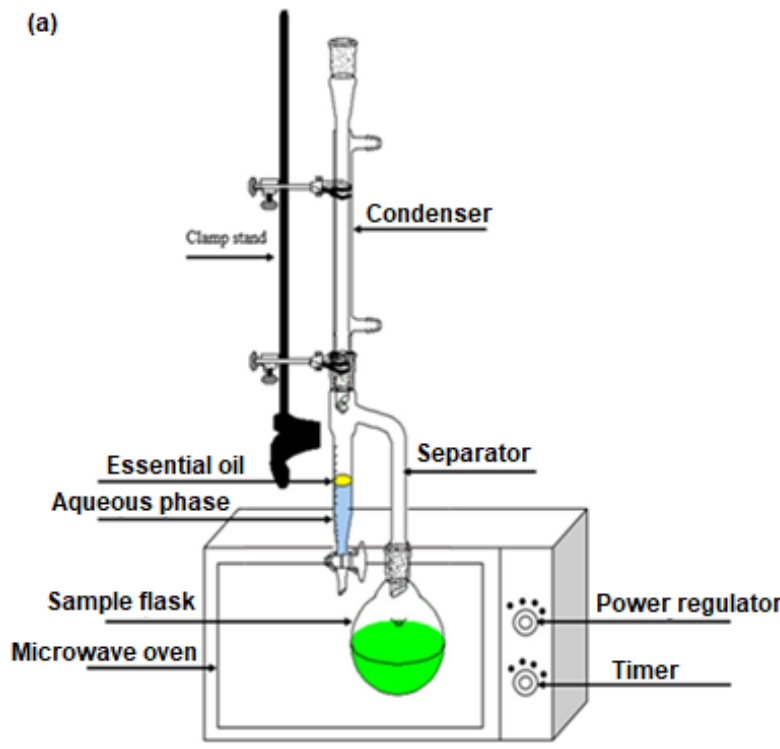

Fig 1. Lemongrass oil extraction system in this study (b) Hydrodistillation method

obtained using the following equation (1):

$\mathrm{Y}=\frac{\mathrm{V}}{\mathrm{m}} * 100$

where: Y: Yield (\%); V: Volume of essential oil (mL) obtained; $\mathrm{m}$ : Amount of raw material (g) used.

Gas Chromatography-Mass Spectrometry (GC-MS) is used to analyze the components contained in essential oils of all two extraction methods. To be specific, $50 \mu \mathrm{L}$ of essential oil sample was introduced in $1.0 \mathrm{~mL}$ of $n$-hexane. The instrument used was GC Agilent $6890 \mathrm{~N}$ equipped with MS 5973 inert. HP5-MS column was used with head column pressure of 9.3 psi. GC-MS spectra were obtained under the following conditions: carrier gas He; flow rate $1.0 \mathrm{~mL} / \mathrm{min}$; split 1:100; injection volume $1.0 \mu \mathrm{L}$; injection temperature $250^{\circ} \mathrm{C}$; oven temperature progress included an initial hold at $50{ }^{\circ} \mathrm{C}$ for $2 \mathrm{~min}$, a rise to $80^{\circ} \mathrm{C}$ at $2{ }^{\circ} \mathrm{C} / \mathrm{min}$, a rise to $150^{\circ} \mathrm{C}$ at $5{ }^{\circ} \mathrm{C} / \mathrm{min}$, a rise to $200^{\circ} \mathrm{C}$ at $10^{\circ} \mathrm{C} / \mathrm{min}$ and a rise to $300^{\circ} \mathrm{C}$ at $20^{\circ} \mathrm{C} / \mathrm{min}$ for $5 \mathrm{~min}$.

\section{- RESULTS AND DISCUSSION}

\section{Optimizing the Extraction of Essential Oils by MAHD}

\section{Effect of the size of raw material}

Effect of the size of raw material on extraction yield of lemongrass (C. citratus) at the fixed raw material to water ratio of 1:3 after $90 \mathrm{~min}$ with microwave power at $500 \mathrm{~W}$

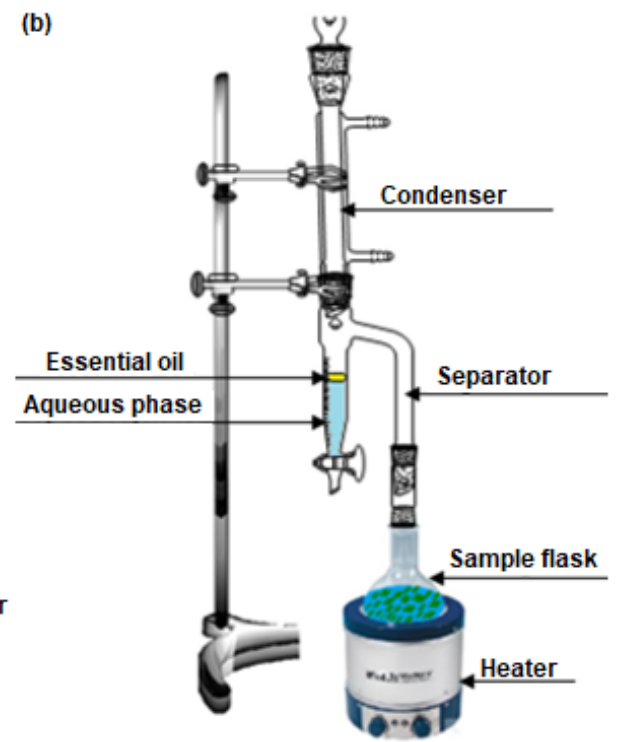

(a) Microwave-assisted hydrodistillation method,

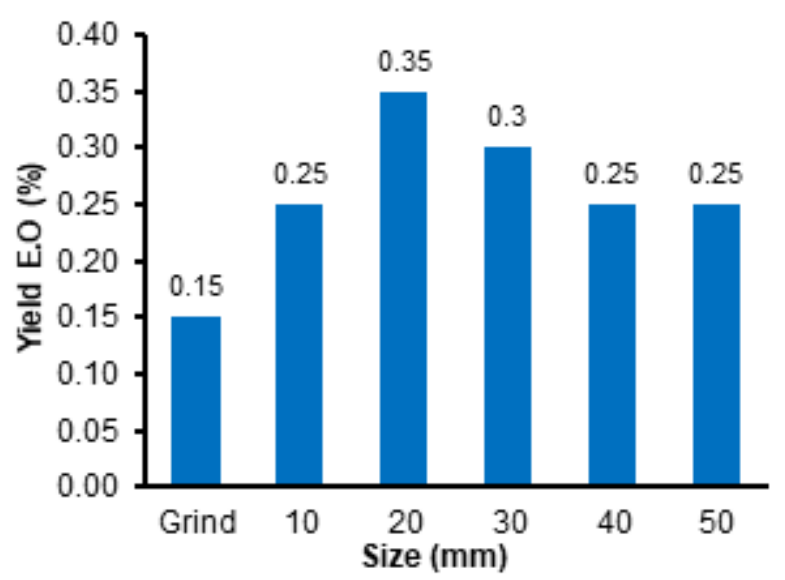

Fig 2. The effect of material size on lemongrass oil extraction process $(\mathrm{mm})$

is shown in Fig. 2.

According to Fig. 2, E.O yield increases as raw material size decreases $(0.25 \%$ at $50 \mathrm{~mm}$ up to $0.35 \%$ at $20 \mathrm{~mm}$ size), but to a certain size, this yield no longer increases but decreases. This is explained by the size of the material; when the cells contain oil is broken, the water quickly diffuses into the E.O bag of lemongrass, quickly pushing the oil outside under the effect of microwave leading to higher yield. However, if the size too small, the E.O will be lost in the cutting process, resulting in loss of efficiency of E.O. obtained. Therefore, the size of lemongrass leaves was chosen as $20 \mathrm{~mm}$. 


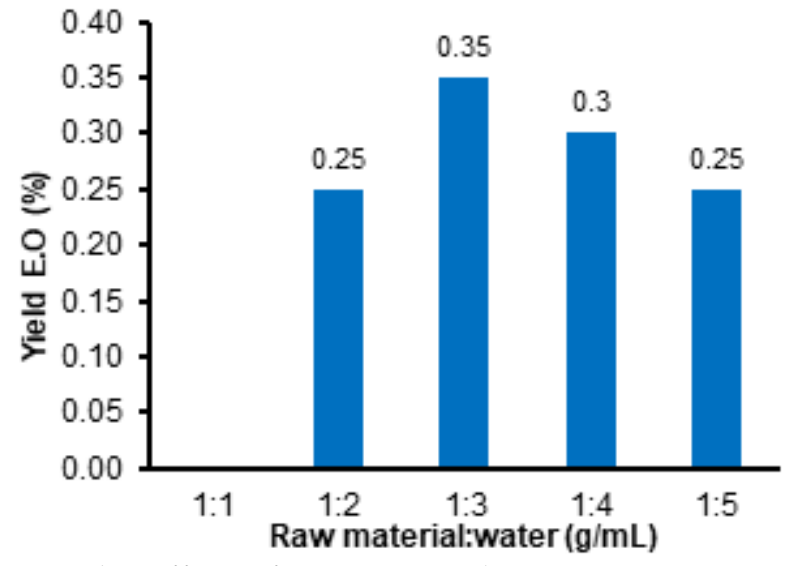

Fig 3. The effect of raw material to water ratio on the lemongrass oil extraction process $(\mathrm{g} / \mathrm{mL})$

\section{Effect of water to raw material ratio on yield}

Fig. 3 demonstrated the effect of various raw material to water ratio on lemongrass oil yield with the size material of $20 \mathrm{~mm}$, microwave power level of $500 \mathrm{~W}$ and at $90 \mathrm{~min}$ for extraction time. The mass of lemongrass leaves for all experiments in this survey is $100 \mathrm{~g}$. By increasing the raw material to water ratio from 1:2 to $1: 3$, the extracted oil yield increased from $0.25 \%$ to $0.35 \%$. From the ratio of $1: 3$ to $1: 4$ and from $1: 4$ to $1: 5$, the extracted oil yield decreased to $0.3 \%$ and $0.25 \%$ respectively. During an extraction by MAHD, the heat of the microwave will osmose from within the material, break up the bag of essential oils and entrain the oils by steam. If the amount of water is insufficient to dissolve the mixture of colloids and salt-wrapped bags of essential oil, the essential oil cannot escape from the oil or a fire can break out (as raw material to water ratio $=1: 1$ ). Using more water to extract, the greater the diffusion of oil into the water. Water is easily absorbed into the material, and soluble components should be extracted, so the yield of extracting essential oils increase. However, excessive water will dissolve or emulsify the oil, reducing the amount of oil obtained and in turn the economic efficiency of the extraction process due to increased energy consumption and prolonged time of heat extraction. As shown in Fig. 3, the ratio of raw materials to water of $1: 3(\mathrm{~g} / \mathrm{mL})$ gives the best result of $0.35 \%$ yield for subsequent experiments.

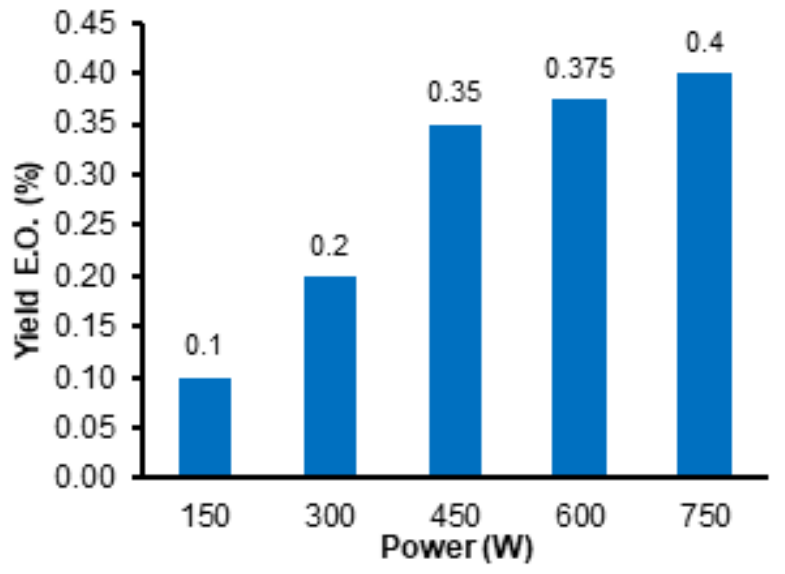

Fig 4. The effect of microwave power on the lemongrass oil extraction process (W)

\section{Effect of microwave power on yield}

Microwave power is one of the factors that affect the lemongrass extraction process. Experimental investigations at different power levels such as 150,300 , 450,600 and $750 \mathrm{~W}$ with the size lemongrass leaves is $20 \mathrm{~mm}$ in length and $90 \mathrm{~min}$ for time, and the raw material to water is 1:3. In Fig. 4, the obtained yields were $0.1,0.2,0.35,0.375$ and $0.4 \%$ at $150,300,450,600$ and $750 \mathrm{~W}$ power, respectively. Clearly, high microwave power led to a better yield of the oil but only to a certain limit of power level. It is because higher the temperature, caused by increased microwave power, incites the movement of the constituents, subsequently raising the velocity of chaotic movement of components in the mixture. This facilitates the diffusion process and allows greater water penetration into the material layer. The surface contact area between the material and water also gets enlarged, thus increasing the efficiency of extraction. However, excessive heat could generate cost inefficiency and cause temperature-sensitive substances in the oil to decompose, affecting the yield of extraction and the quality of the essential oil adversely. Therefore, microwave power of $450 \mathrm{~W}$ is selected to use for subsequent experiments.

\section{Effect of extraction time on yield}

The effect of the time in the extraction of lemongrass oil is shown in Fig. 5. The extraction time depends on the following factors: raw materials, solvent 
ratio, and temperature. Visually, from 30 to $90 \mathrm{~min}$, the extraction time is proportional to oil yield. However, with the extraction time being extended beyond $90 \mathrm{~min}$, the percentages of recovered oil seem to be static at $0.35 \%$. In addition, prolonged exposure with heat may cause some substances to be denatured which could in turn impair the quality of the produced oil. The longer the extraction time, the more oil is obtained. However, when extending the extraction time to a certain limit, the amount of recovered oil does not increase further and may affect the quality of the product because some substances can be denatured due to prolonged exposure with temperature. It is also crucial to determine the optimal extraction time since it concerns energy consumption and production cost. With the survey period ranging from $0.15 \%$ yield at $30 \mathrm{~min}$ to $0.35 \%$ at $150 \mathrm{~min}$, we chose $90 \mathrm{~min}$ for lemongrass oil extraction process by microwave.

\section{Comparison of Lemongrass (Cymbopogon citratus) Oil Obtained by Conventional Hydrodistillation Method}

The essential oils from lemongrass leaves are extracted by MAHD, and traditional hydrodistillation method has obtained yield of $0.35 \% \mathrm{~S}(\mathrm{v} / \mathrm{w})$ in the MAHD and $0.15 \%(\mathrm{v} / \mathrm{w})$ in the HD. MAHD condition was optimized regarding delivering the size material, raw material to water ratio, microwave power and extraction time. Table 1 shows the oil yields of extraction at different conditions. Time extraction lemongrass oil of MAHD method was four times shorter than that of HD procedure. HD method takes $360 \mathrm{~min}$ to complete the extraction process, whereas $90 \mathrm{~min}$ is sufficient for a complete extraction by the MAHD method because raw material

Table 1. Comparison of factors of different methods

\begin{tabular}{lcc}
\hline Method & MAHD & HD \\
\hline $\begin{array}{l}\text { Material to water } \\
\text { ratio }(\mathrm{g} / \mathrm{mL})\end{array}$ & $1: 3$ & $1: 4$ \\
$\begin{array}{l}\text { Time extraction } \\
(\mathrm{min})\end{array}$ & 90 & 360 \\
Yields $(\%, \mathrm{v} / \mathrm{w})$ & 0.35 & 0.15 \\
\hline
\end{tabular}

and water can diffuse and exchange more effectively and quickly during microwave radiation so that essential oil can be extracted quickly and completely [7]. This is the advantage of using the microwave in the extraction process. This method will help us save a large amount of time with large amounts of material on the industrial scale.

The results of GC-MS analyses of the essential oils were given in Table 2 and GC-MS chromatogram obtained for a sample of lemongrass oil in Fig. 6. Citral (neral and geranial) is the highest content in all two methods. However, the MAHD method was the highest at $93.28 \%$, while the HD was $83.85 \%$. In addition, the composition of myrcene, eudesm-7(11)-en-4-ol, nerol was also compared between the two extraction methods. However, the GC-MS chromatogram of the HD oil method has many other impurities compared to the oil obtained by the MAHD method, so the oil from the MAHD method has a higher purity than the HD oil. This difference can be explained because of the radiation of the

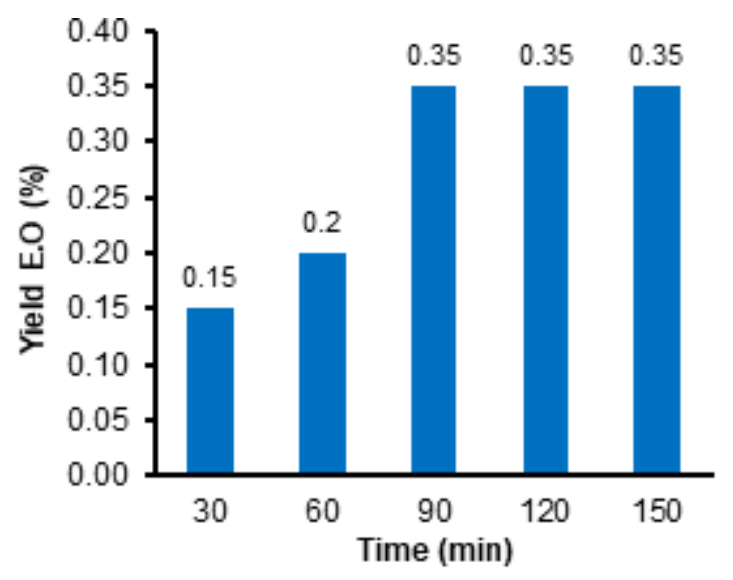

Fig 5. The effect of time on lemongrass oil extraction process ( $\mathrm{min}$ )

Table 2. Component of lemongrass oil obtained by MAHD, HD method

\begin{tabular}{lcr}
\hline Component & MAHD (\%) & HD (\%) \\
\hline Neral & 34.11 & 35.13 \\
Myrcene & 0.91 & 3.61 \\
Geranial & 59.17 & 48.72 \\
Eudesm-7(11)-en-4-ol & 2.20 & 5.03 \\
\hline
\end{tabular}




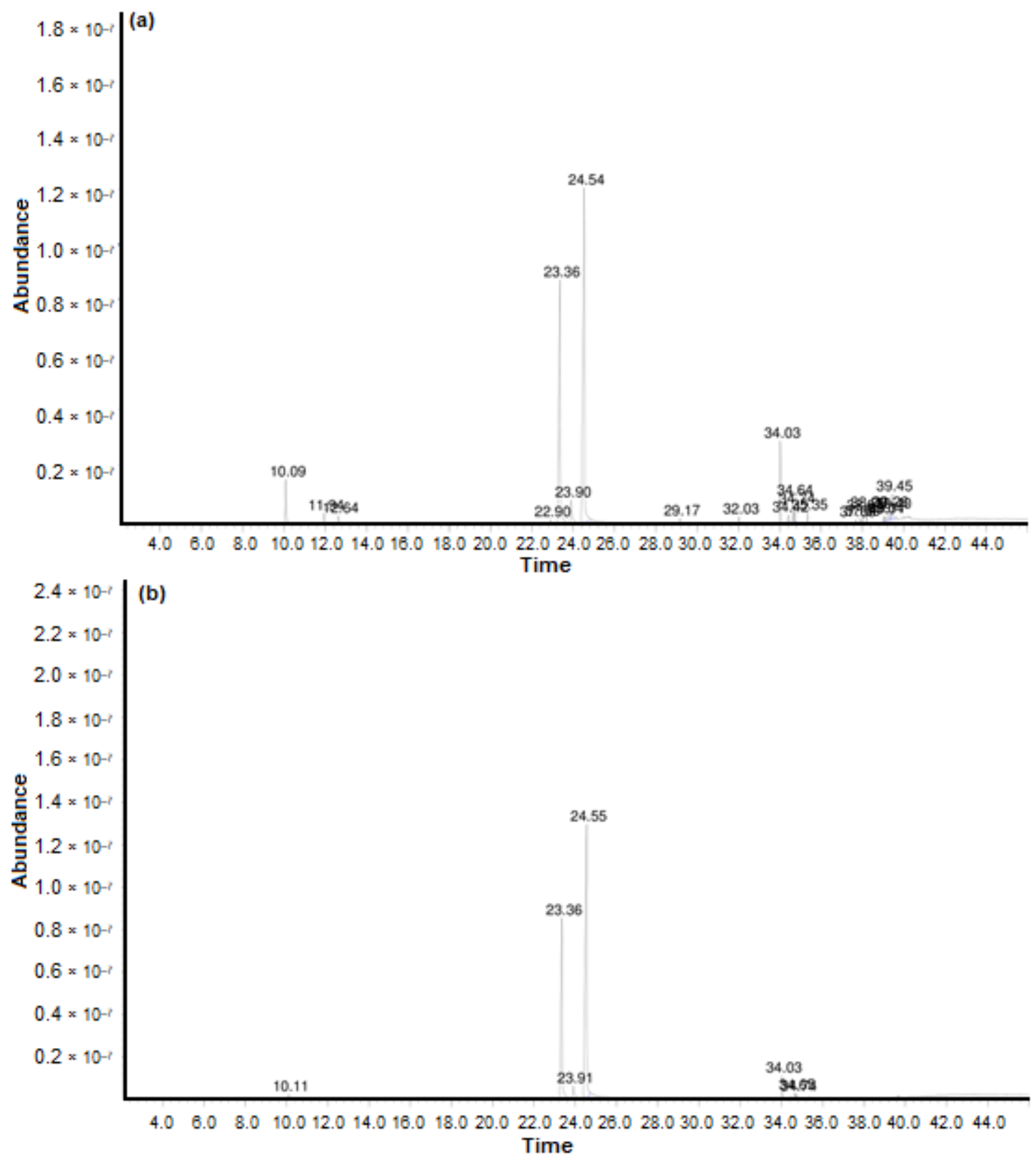

Fig 6. GC-MS chromatogram obtained for a sample of lemongrass oil by (a) HD, (b) MAHD

microwave inside the material, creating heat with water molecules and breaking down the essential oil [10]. All these results have proved that microwave helps shorten the time of extraction process, but without causing a significant effect in the volatile oil composition. The quantity and quality oil may vary according to different climatic and geographical conditions, harvesting time and method of extraction.

\section{- CONCLUSION}

The microwave-assisted hydrodistillation method has been compared with the conventional hydrodistillation method for the extraction of essential oil from lemongrass living in Vietnam. According to the result of GC-MS, there was no significant difference between the components of essential oil obtained by 
MAHD and those obtained by the traditional extraction method. All two methods use lemongrass leaves size of $20 \mathrm{~mm}$ in length. In MAHD, the raw material to water is $1: 3(\mathrm{~g} / \mathrm{mL})$, at $90 \mathrm{~min}$, and microwave power is $450 \mathrm{~W}$. Meanwhile, the traditional method uses a ratio of 1:4 $(\mathrm{g} / \mathrm{mL})$ and extraction time in $360 \mathrm{~min}$. The yields of MAHD and HD method are $0.35 \%$ and $0.2 \%$, respectively. From the results of GC-MS analyses, the MAHD method was highest at $93.28 \%$ Citral composition, while the figure of the HD was $83.85 \%$. Therefore, the MAHD method could be considered as a method to overcome the limitations of traditional distillation methods and as a green technology that is environmental friendly in industrial-scale E.O. production.

\section{- ACKNOWLEDGMENTS}

This research is funded by the NTTU Foundation for Science and Technology Development.

\section{- REFERENCES}

[1] Jeyaratnam, N., Nour, A.H., Kantasamy, R., and Akindoyo, J.O., 2017, Microwave assisted hydrodistillation - An overview of mechanism and heating properties, Aust. J. Basic Appl. Sci., 11 (3), 22-29.

[2] Amaresh, A., Guha, P., Khan, S., and Zari, S.R., 2017, Comparative study of microwave assisted hydrodistillation with conventional hydro-distillation for extraction of essential oil from Piper betle L., Biosci. Biotechnol. Res. Asia, 14 (1), 401-407.

[3] Kusuma, H.S., and Mahfud, M., 2016, Response surface methodology for optimization studies of microwave-assisted extraction of sandalwood oil, $J$. Mater. Environ. Sci., 7 (6), 1958-1971.

[4] Mathialagan, R., 2012, Extraction and Characterization of essential oil from ginger (Zingiber officinale Roscoe) and lemongrass (Cymbopogon citratus) by Microwave-Assisted Hydrodistillation (MAHD), Undergraduate Thesis, Faculty of Chemical and Natural Resource Engineering, Universiti Malaysia Pahang.

[5] Wei, L., Zhang, Y., and Jiang, B., 2013, Comparison of microwave-assisted hydrodistillation with the traditional hydrodistillation method in the extraction of essential oils from dwarfed Cinnamomum camphora var. Linaolifera Fujita leaves and twigs, Adv. J. Food Sci. Technol., 5 (11), 1436-1442.

[6] Karakaya, S., El, S.N., Karagozlu, N., Sahin, S., Sumnu, G., and Bayramoglu, B., 2014, Microwaveassisted hydrodistillation of essential oil from rosemary, J. Food Sci. Technol., 51 (6), 1056-1065.

[7] Jiang, Z.T., Feng, X., Li, R., and Wang, Y., 2013, Composition comparison of essential oils extracted by classical hydrodistillation and microwaveassisted hydrodistillation from Pimenta dioica, J. Essent. Oil Bear. Plants, 16 (1), 45-50.

[8] Kusuma, H.S., and Mahfud, M., 2017, Microwaveassisted hydrodistillation for extraction of essential oil from patchouli (Pogostemon cablin) leaves, Period. Polytech. Chem. Eng., 61 (2), 82-92.

[9] Rezvanpanah, S., Rezaei, K., Razavi, S.H., and Moini, S., 2008, Use of microwave-assisted hydrodistillation to extract the essential oils from Satureja hortensis and Satureja montana, Food Sci. Technol. Res., 14 (3), 311-314.

[10] Asghari, J., Touli, C.K., and Mazaheritehrani, M., 2012, Microwave-assisted hydrodistillation of essential oils from Echinophora platyloba DC, J. Med. Plants Res., 6 (28), 4475-4480.

[11] Golmakani, M.T., and Moayyedi, M., 2015, Comparison of heat and mass transfer of different microwave-assisted extraction methods of essential oil from Citrus limon (Lisbon variety) peel, Food Sci. Nutr., 3 (6), 506-518.

[12] Kusuma, H.S., and Mahfud, M., 2017, Comparison of kinetic models of oil extraction from sandalwood by microwave-assisted hydrodistillation, Int. Food Res. J., 24 (4), 1697-1702.

[13] Moradalizadeh, M., Samadi, N., and Rajaei, P., 2013, Comparison of hydrodistillation, microwave hydrodistillation and solvent-free microwave methods in analysis of the essential oils from aerial parts of Haplophyllum robustum Bge. by GC/MS method, Int. J. Adv. Biol. Biomed. Res., 1 (9), 10581067. 
[14] Farjam, M.H., Zardosht, M., and Joukar, M., 2011, Comparison of microwave-assisted hydrodistillation and traditional hydrodistillation methods for extraction of the Vitex pseudo-negundo essential oils, Adv. Environ. Biol., 8 (21), 82-85.

[15] Mathialagan, R., Nour, A.H., Sulaiman, Z.A., Nour, A.H., and Raj, S.T., 2014, Comparison of chemical composition and toxicity of essential oils from lemongrass (Cymbopogon citratus) extracted with microwave-assisted hydrodistillation (MAH) and conventional hydrodistillation (HD) methods, J. Adv. Nat. Sci., 1 (1), 10-15.

[16] Jeyaratnam, N., Nour, A.H., and Akindoyo, J.O., 2016, Comparative study between hydrodistillation and microwave-assisted hydrodistillation for extraction of Cinnamomum cassia oil, ARPN J. Eng. Appl. Sci., 11 (4), 2647-2652.

[17] Skaria, B.P., Joy, P.P., Mathew, G., Mathew, S., and Joseph, A., 2006, "Lemongrass" in Handbook of Herbs and Spices: Volume 3, Eds., Peter, K.V., CRC Press; Woodhead Publishing, Cambridge, UK, 400419.
[18] Shah, G., Shri, R., Panchal, V., Sharma, N., Singh, B., and Mann, A., 2011, Scientific basis for the therapeutic use of Cymbopogon citratus, Stapf (Lemon grass), J. Adv. Pharm. Technol. Res., 2 (1), 3-8.

[19] Mosquera, T., Noriega, P., Cornejo, J., and Pardo, M.L., 2016, Biological activity of Cymbopogon citratus (DC) Stapf and its potential cosmetic activities, Int. J. Phytocosmet. Nat. Ingredients, 3 (7), 1-7.

[20] Okoh, O.O., Sadimenko, A.P., and Afolayan, A.J., 2010, Comparative evaluation of the antibacterial activities of the essential oils of Rosmarinus officinalis L. obtained by hydrodistillation and solvent free microwave extraction methods, Food Chem., 120 (1), 308-312.

[21] Madivoli, E.S., Gitu, L., and Gumba, E., 2012, Isolation and identification of essential oils from Cymbopogon citratus (Stapf) DC using GC-MS and FT-IR, Chem. Mater. Res., 2 (4), 13-23.

[22] Parikh, J.K., and Desai, M.A., 2011, Hydrodistillation of essential oil from Cymbopogon flexuosus, Int. J. Food Eng., 7 (1), 1-9. 